\title{
Evaluation of three models for predicting Venturia inaequalis ascospore release in Southern Brazil
}

\author{
S.A.M. Alves ${ }^{1}$ and R.M. Beresford ${ }^{2}$ \\ ${ }^{1}$ Embrapa Grape and Wine, BR 285, km 115, Vacaria, RS, Brazil \\ ${ }^{2}$ The New Zealand Institute for Plant E Food Research Limited, Private Bag 92-169, \\ Auckland, New Zealand \\ Corresponding author: silvio.alves@embrapa.br
}

\begin{abstract}
Ascospores of Venturia inaequalis constitute the principal source of primary inoculum for epidemics of apple black spot (scab). Mathematical models that describe ascospore release have been developed in USA, New Zealand and Italy. These models are based upon degree-day accumulation. In this work, the seasonal pattern of released ascospores of $V$. inaequalis in Vacaria, Brazil, was evaluated. During four apple growth seasons (2009 to 2012) the natural release of ascospores from five orchards was recorded. The cumulative percentage of ascospore release was predicted using three different degreeday models. The released ascospore data showed the best fit to the model developed in Italy, with a start date of 22 August rather than the phenological stage of apple bud break. It is concluded that in regions with warm winter temperatures, models that use bud break to initiate ascospore maturation will tend to underestimate availability of ascospores at the beginning of the apple growth season.
\end{abstract}

Keywords Venturia inaequalis, epidemiology, apple scab, Malus domestica.

\section{INTRODUCTION}

The causal agent of black spot (scab), Venturia inaequalis, overwinters as immature pseudothecia in the fallen leaves of apple. In spring, pseudothecia mature and release ascospores following wetting by rain (MacHardy 1996). The disease is generally controlled by the repeated application of fungicides directed against ascospore infection. When the ascospore supply is depleted in early summer, the interval between fungicide sprays increases and, in some cases, further spraying against black spot may not be necessary.

The maturation of a pseudothecial population has three phases, lag, accelerated and final, and the accumulated percentage of available ascospores shows a sigmoid curve (MacHardy 1996). The maximum rate of ascospore release occurs when $50 \%$ of pseudothecia have matured and often coincides with the pre-bloom expansion of newly emerging leaves and flowers, both of which are highly susceptible to infection.

Mathematical models that describe the progress of pseudothecial maturation over time have been developed in USA (Gadoury \& MacHardy 1982), New Zealand (Beresford 1999) and Italy (Rossi et al. 2000). These models have been developed either using direct observations of pseudothecial maturity or counts of released ascospores, which averaged over a season reflect pseudothecial maturation if rainfall is reasonably continuous. 
Because pseudothecial maturation occurs faster at warmer temperatures, these models use degree-day accumulation above $0^{\circ} \mathrm{C}$ as the driving variable. The date for the start of degreeday accumulation (biofix) is very important (Gadoury \& MacHardy 1982; Eikemo et al. 2011) and the three models use different ways of defining the biofix. The addition of a restriction on the accumulation of degree-days proved useful when the model developed in the USA was tested in a region in Norway with protracted dry periods (MacHardy 1996; Stensvand et al. 2005). In this regard, the model developed in Italy is the most restrictive because it accumulates only when the leaves are wet. Furthermore this model differs from the other two models because the estimates are based on hourly data, whereas the USA and New Zealand models use daily data.

Weather in spring and early summer in the northeast of Rio Grande do Sul State, Brazil, varies greatly from year to year. The average rainfall (1961-1990) in September, October and November in Vacaria is 165, 163 and 121 $\mathrm{mm}$, respectively (IPAGRO 1989). Black spot control is easily achieved in some years, but it is difficult in others, as determined by the way that rainfall events, ascospore availability and spray timing interact. Models that use weather parameters to predict availability of ascospores are important tools for enabling more efficient use of fungicides for disease control. In this work, seasonal counts of released $V$. inaequalis ascospores were used to evaluate three models for predicting ascospore release.

\section{MATERIALS AND METHODS}

\section{Ascospore release, tree phenology and weather monitoring}

The natural release of ascospores from five orchards located near Embrapa, Vacaria, and within a $25 \mathrm{~km}$ radius of each other, was recorded over four consecutive seasons (2009 to 2012). Ascospore release was monitored by counting ascospores naturally discharged onto glass microscope slides (Manktelow \& Beresford 1995). Scabbed apple leaves (cv. 'Gala') were collected from five unsprayed orchards in May of each year at leaf fall. Twenty leaves were placed between two layers of galvanised wire mesh (an $18 \times 18 \mathrm{~cm}$ sheet of a $1.5 \times 1.5 \mathrm{~cm}$ grid), taking care to ensure that the leaf surfaces in the mesh were orientated as collected from the orchard floor. One wire mesh was prepared for each orchard. The meshes overwintered outside and were protected from fungicide sprays, at Embrapa Grape and Wine, Vacaria, Brazil.

From August each year, three glass microscope slides $(76 \times 26 \mathrm{~mm})$ were placed on the meshes. Slides were removed and examined after each rain event (rain $>0.2 \mathrm{~mm}$ ) and replaced with clean slides in exactly the same position over the litter. Counts continued until the last week of December.

To allow ascospore release patterns to be referenced to tree phenology, the development of 'Gala' shoots was recorded by visually assessing the reproductive growth stage of shoots at about weekly intervals, using a method similar to that described by Beresford \& Manktelow (1995). An automatic weather station (model MAWS301, Vaisala, Finland) at Embrapa Grape and Wine, Vacaria (28³0'48”S, 5052'58'W), provided hourly records of temperature, relative humidity and rainfall.

\section{Comparison between observed and modelled ascospore release}

The cumulative percentage of observed ascospore release was plotted against thermal time (Celsius degree-day accumulation above base $0^{\circ} \mathrm{C}$ ). The observed ascospore release was compared with the cumulative percentage of matured ascospores (y) predicted using three different degree-day models:

$y=\left\{1 / 2^{\star}\left[1+\operatorname{erf}\left(0.01^{\star} \mathrm{DD}-2.51\right)\right]\right\}^{\star} 100$, Gadoury

\& MacHardy (1982)

$y=100 / 1+\exp -0.01^{\star}(\mathrm{DD}-534)$, Beresford (1999)

$y=1 /\left[1+\exp \left(6.89-0.035^{\star} \mathrm{DD}\right)\right]$, Rossi et al.

(2000)

where DD is the degree-day accumulation. The three models tested all produce a symmetrical sigmoid response. The USA model is probitbased and the New Zealand and Italy models are logistic-based. The degree-day accumulation to reach $50 \%\left(\mathrm{DD}_{50 \%}\right)$ for each model is 251,534 and 197 for USA, New Zealand and Italy, respectively, 
but for the Italian model, degree-days are only accumulated when there is leaf wetness.

For each year, two criteria were tested as the biofix for degree-day accumulations: (1) the date at which at least $50 \%$ of fruit buds of apple cv. 'Gala' had reached the green tip stage (Gadoury \& MacHardy 1982) and (2) 22 August (Beresford 1999).

Performance of the models was evaluated by linear regression of observed ascospore discharge against ascospore maturity predicted by each model. The slope and intercept of the regression line were tested for equality to 1 and 0 , respectively, by Student's $t$ test. If the $t$ tests for slope $(b)$ or intercept $(a)$ were not significant $(\mathrm{P}>0.05)$, the model was considered an accurate estimator of the data.

\section{RESULTS}

The date that observed cumulative ascospore release reached $50 \%$ of each season's total release was relatively early in 2011 (2 days before green tip) and 2012 (the same date as green tip). The early ascospore release in those two years coincided with early green tip and a very protected period between green tip and full bloom (Figure 1). In 2009 and 2010, green tip occurred later and also the period between green tip and full bloom was much shorter. In 2009 $50 \%$ release occurred 4 days after green tip and in 2010 it occurred 22 days after green tip. The date of $50 \%$ ascospore release in relation to full
2012

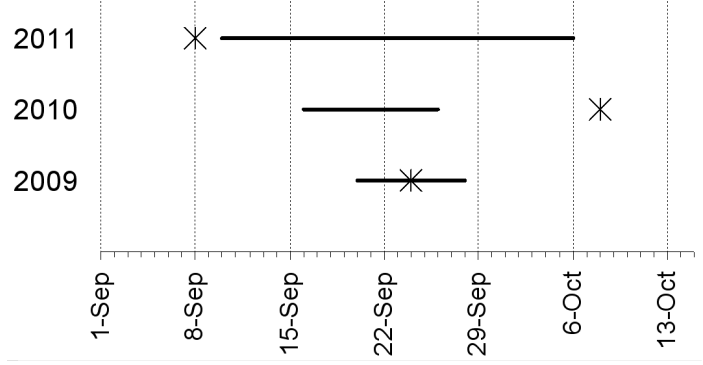

Figure 1 Dates for 50\% observed ascospore release (asterisks) in each of 4 years near Vacaria, Brazil, and the period between green tip and full bloom (lines) for 'Gala' apple.

bloom was also very variable, being 2 days before in 2009, 12 days after in 2010, 28 days before in 2011 and 20 days before in 2012 .

The linear regression analyses comparing the predicted cumulative ascospore release with the observed cumulative ascospore release for the 22 August biofix (Table 1) and for the green tip biofix (Table 2) demonstrated that, over all 4 years, the Italian model with a biofix to start degreeday accumulation from 22 August produced the highest coefficient of determination $\left(\mathrm{R}^{2}\right)$ of 0.79 (Table 1 and Figure 2).

Among the regressions for each year, for which the intercept and slope were 1 and 0 , respectively, the highest coefficients of determination were calculated in $2012(0.85,0.79$ and 0.80 for USA,

Table 1 Linear regression equations of observed release of Venturia inaequalis ascospores from 'Gala' apple leaves versus predicted number of mature pseudothecia estimated by three models developed in USA, New Zealand or Italy. The start date criterion was 22 August.

\begin{tabular}{lccc}
\hline Year & \multicolumn{1}{c}{ USA } & New Zealand & Italy \\
\hline 2009 & $\mathrm{y}=0.80 \mathrm{x}+38.82(0.71)^{1}$ & $\mathrm{y}=1.07 \mathrm{x}-12.99(0.89)$ & $\mathrm{y}=1.26 \mathrm{x}-5.51(0.84)$ \\
2010 & $\mathrm{y}=0.24 \mathrm{x}+80.55(0.14)$ & $\mathrm{y}=0.74 \mathrm{x}+33.28(0.71)$ & $\mathrm{y}=0.93 \mathrm{x}+11.89(0.90)$ \\
2011 & $\mathrm{y}=1.18 \mathrm{x}-12.21(0.90)$ & $\mathrm{y}=1.00 \mathrm{x}-24.39(0.73)$ & $\mathrm{y}=1.18 \mathrm{x}-20.61(0.91)$ \\
2012 & $\mathbf{y}=\mathbf{1 . 0 4 x}+\mathbf{1 . 2 2 ( 0 . 8 5 )}$ & $\mathbf{y}=\mathbf{1 . 0 2 x}-\mathbf{2 1 . 0 5 ( 0 . 7 9 )}$ & $\mathbf{y}=\mathbf{1 . 1 3 x}-\mathbf{2 5 . 3 7 ( \mathbf { 0 . 8 0 } )}$ \\
All years & $\mathrm{y}=0.67 \mathrm{x}+38.53(0.45)$ & $\mathrm{y}=0.82 \mathrm{x}+1.35(0.61)$ & $\mathbf{y}=\mathbf{1 . 0 2} \mathbf{x}-\mathbf{2 . 8 9}(\mathbf{0 . 7 9})$ \\
\hline
\end{tabular}

${ }^{1}$ Results from linear regressions of observed $(\mathrm{x})$ versus predicted $(\mathrm{y})$, shown as coefficient of determination $\left(\mathrm{R}^{2}\right)$. Slope and intercept of the regression line were tested for equality to 1 and 0 , respectively, by Student's $t$ test. Fitted lines where slope and intercept are equal to 1 and 0 , respectively, are marked in bold. 
Table 2 Linear regression equations of observed release of Venturia inaequalis ascospores from 'Gala' apple leaves versus predicted number of mature pseudothecia estimated by three models developed in USA, New Zealand or Italy. The start date criterion was the date at which $50 \%$ of fruit buds had reached the green tip stage.

\begin{tabular}{lccc}
\hline Year & \multicolumn{1}{c}{ USA } & NZ & ITALY \\
\hline 2009 & $\mathrm{y}=1.35 \mathrm{x}-32.00(0.77)^{1}$ & $\mathrm{y}=0.47 \mathrm{x}-12.15(0.58)$ & $\mathrm{y}=1.09 \mathrm{x}-27.72(0.69)$ \\
2010 & $\mathrm{y}=0.92 \mathrm{x}+19.81(0.76)$ & $\mathrm{y}=0.51 \mathrm{x}-0.71(0.64)$ & $\mathbf{y}=\mathbf{0 . 6 9 x}-\mathbf{4 . 7 3}(\mathbf{0 . 5 6})$ \\
2011 & $\mathrm{y}=1.25 \mathrm{x}-25.72(0.92)$ & $\mathbf{y}=\mathbf{0 . 8 4 x}-\mathbf{2 3 . 9 8 ( \mathbf { 0 . 6 0 } )}$ & $\mathrm{y}=1.13 \mathrm{x}-32.70(0.73)$ \\
2012 & $\mathrm{y}=1.53 \mathrm{x}-55.07(0.90)$ & $\mathrm{y}=0.82 \mathrm{x}-40.18(0.35)$ & $\mathbf{y}=\mathbf{1 . 1 8 x}-\mathbf{5 2 . 2 8}(\mathbf{0 . 5 9})$ \\
All years & $\mathbf{y}=\mathbf{1 . 0 6 x} \mathbf{- 6 . 9 8 ( 0 . 7 4 )}$ & $\mathrm{y}=0.60 \mathrm{x}-12.07(0.50)$ & $\mathrm{y}=0.90 \mathrm{x}-18.43(0.63)$ \\
\hline
\end{tabular}

${ }^{1}$ Results from linear regressions of observed $(\mathrm{x})$ versus predicted $(\mathrm{y})$, shown as coefficient of determination $\left(\mathrm{R}^{2}\right)$. Slope and intercept of the regression line were tested for equality to 1 and 0 , respectively, by Student's $t$ test. Fitted lines where slope and intercept are equal to 1 and 0 , respectively, are marked in bold.

New Zealand and Italy respectively) with a biofix of 22 August. The NZ and Italy models had higher $\mathrm{R}^{2}$ values when estimated from the 22 August biofix. In contrast, the USA model showed higher $\mathrm{R}^{2}$ values when estimated from green tip biofix.

\section{DISCUSSION}

Of the three models examined by regression analyses in this study, the Italian model with a biofix for starting degree-day accumulation of 22 August was the most accurate for predicting the 4 years of $V$. inaequalis ascospore release from Southern Brazil. The Italian model has restrictions on accumulated degree-days, which are accumulated only for hours when there is

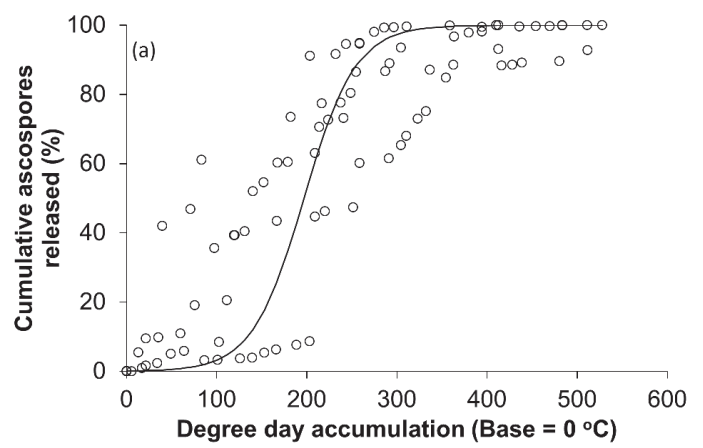

leaf wetness. The USA model was developed by Gadoury \& MacHardy (1982) to estimate cumulative pseudothecial maturity, not cumulative ascospore release. However, under conditions of frequent rainfall, this model can be used to estimate ascospore release (Gadoury et al. 2004). The New Zealand model was developed from ascospore data collected in five regions of New Zealand (Manktelow \& Beresford 1995). The optimum biofix for starting degree-day accumulation from that study was 22 August.

In Vacaria, Brazil, the winter period does not always fulfil the bud chilling requirement for commercial apple cultivars (Cardoso et al. 2012) and the time that phenological stages, including

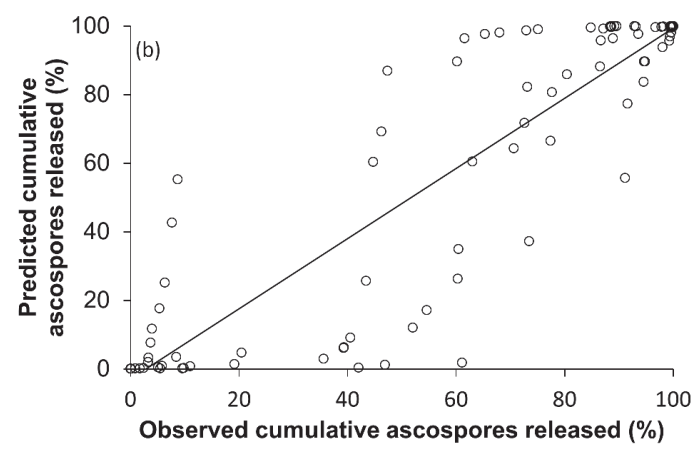

Figure 2 For the Italian ascospore maturation model developed by Rossi et al. (2000), (a) 4 years of Venturia inaequalis ascospore counts from Vacaria, Brazil, as cumulative percentage ascospore release versus degree-day accumulation from 22 August (open circles) and ascospore release predicted by the model (line) and (b) model-predicted cumulative percentage ascospore release versus observed cumulative ascospore release, with the regression line: $y=1.02 x-2.89\left(R^{2}=0.79\right)$. 
green tip and full bloom, occurs is variable, as seen in the present study. This study compared two methods for determining the biofix point for degree-day accumulation, and for all three models, estimates starting from 22 August were better than those starting from green tip. Ascospore release from the leaf litter does not depend on apple bud chilling and occurs earlier in regions with warmer winter temperatures (Manktelow \& Beresford 1995). In the present study ascospore release had reached $50 \%$ by green tip in two of the four years examined. The bud break or green tip growth stages have often been used as a starting point to estimate ascospore release (Stensvand et al. 2005), but in warm temperate (low latitude) regions, like Brazil and northern parts of New Zealand, ascospore release may be well advanced by green tip. This also happens in Northern Victoria, Australia, for Venturia pirina (Eikemo et al. 2011). Therefore, models that use bud break or green tip to initiate ascospore maturation will tend to underestimate availability of ascospores at the beginning of the apple growth season in regions and seasons with warm winter temperatures. With increasing mean temperatures due to global warming this may also become important in higher latitude apple growing regions in the future.

This is the first study to compare models to estimate $V$. inaequalis ascospore release under the climatic conditions of Southern Brazil. An accurate ascospore release model can help apple growers identify the periods of $50 \%$ and $98 \%$ ascospore release for a given season and use this information to reduce fungicide application for disease control. The use of these models in Brazil may help identify seasons when ascospore maturation is well advanced by the green tip stage.

\section{ACKNOWLEDGEMENTS}

We thank laboratory technicians Faustina V. de Lima and Vanderlei C. da Silva for helping us to conduct these experiments.

\section{REFERENCES}

Beresford RM 1999. Validation of an ascospore release prediction model for apple black spot (Venturia inaequalis). Proceedings of the 52nd New Zealand Plant Protection Conference: 148-152.
Beresford RM, Manktelow DWL 1995. Methods for disease assessment in apples, including growth stages, leaf emergence, black spot and powdery mildew. Proceedings of the 48th New Zealand Plant Protection Conference: 98-94.

Cardoso LS, Bergamaschi H, Bosco LC, Paula VA, Marodin GAB, Casamali B, Nachtigall GR 2012. Disponibilidades climáticas para macieira na região de Vacaria, RS. Ciência Rural 42: 1960-1967.

Eikemo H, Gadoury DM, Spotts RA, Villalta O, Creemers P, Seem RC, Stensvand A 2011. Evaluation of six models to estimate ascospore maturation in Venturia pyrina. Plant Disease 95: 279-284.

Gadoury DM, MacHardy WE 1982. A model to estimate the maturity of ascospores of Venturia inaequalis. Phytopathology 72: 901904.

Gadoury DM, Seem RC, MacHardy WE, Wilcox WF, Rosenberger DA, Stensvand A 2004. A comparison of methods used to estimate the maturity and release of ascospores of Venturia inaequalis. Plant Disease 88: 869-874.

IPAGRO 1989. Atlas agroclimático do estado do Rio Grande do Sul. Porto Alegre, Brasil. 102 p. MacHardy WE 1996. Apple Scab: Biology, Epidemiology, and Management. American Phytopathological Society, St. Paul, USA. 570 p.

Manktelow DWL, Beresford RM 1995. Evaluation of an ascospore monitoring method for Venturia inaequalis to improve apple black spot fungicide management. Proceedings of the 48th New Zealand Plant Protection Conference: 78-82.

Rossi V, Marinelli M, Ponti I, Giosuè S, Bugiani $\mathrm{R} 2000$. A new model estimating the seasonal pattern of air-borne ascospores of Venturia inaequalis (Cooke) Wint. in relation to weather conditions. Journal of Plant Pathology 82: 111-118.

Stensvand A., Eikemo H, Gadoury DM, Seem RC 2005. Use of a rainfall frequency threshold to adjust a degree-day model of ascospore maturity of Venturia inaequalis. Plant Disease 89: 198-202. 